\title{
Creating a Child Friendly Psychosocial Learning Environment in Mathematics: A Case of Problem Solving in Grade 6
}

\author{
Satsope Maoto \\ Department of Mathematics, Science and Technology Education \\ University of Limpopo, Sovenga, South Africa \\ satsope.maoto@ul.ac.za
}

\section{Doi:10.5901/mjss.2014.v5n23p1048}

\section{Abstract}

This article aims to explore the question, 'How to create a child friendly psychosocial learning environment in teaching young learners mathematics?'. I report on lessons taught during action research collaboration between Joel, a male primary mathematics teacher, and I, a female mathematics educator. I used field-notes, journal entries, and lesson and interview transcripts to construct vignettes of two of the lessons taught by Joel in grade six mathematics teaching in a rural school. The vignettes are constructed using the strategy of narrative analysis. I, thereafter, explore the question in more detail using analysis of narrative strategy. It was found that young learners (aged 11years to 12 years) could direct their own learning if offered opportunities to construct, refine and use their own representations in solving mathematics problems. The psychosocial learning environment created promoted learners' engagement in mathematical reasoning, and search for mathematical connections. This process encompassed a caring attitude, openness and a relaxed mood. Hence, I offer some implications for mathematics teachers with respect to classroom practices, and the teacher-learner interpersonal relationship.

Keywords: child friendly school, psychosocial learning environment

\section{Introduction}

Since 2005, the Child Friendly School (CFS) project has been implemented by South Africa's National Department of Education in partnership with United Nations Children's Fund (UNICEF) under the banner of safe and caring schools (UNICEF, 2010). The main vision of the CFS project is a school where every child has the opportunity to benefit from education and to develop his/her potential to its fullest through a right based, equitable and all inclusive educational experience (Junaid, 2011). The key CFS principles are child-centeredness, inclusiveness, and democratic participation (UNICEF, 2010). For good teaching one of the key aspects becomes the creation of a caring, friendly, healthy, safe, protective, rich and more qualitative learning environment in which all learners are treated with respect (UNICEF, 2010).

According to Frenzel, Pekrun and Goetz (2007) the classroom learning environment embodies more than merely physical space, it consists of the entire learning setting, including instructional processes, teacher-learner relationships, learner-learner relationships and learner attitudes. It refers to the tone, ambience or atmosphere created by a teacher through the relationships developed within the classroom and the way in which instruction is delivered (Aldridge, Fraser \& Ntuli, 2009). Thus, learning environments can be conceptualised in terms of physical component, that is, observable characteristics, such as school buildings, learning support materials used for instruction, and externally observed interactions between and among learners and teachers. Alternatively, learning environments can be conceptualised in terms of psychosocial component, that is, the teachers' or learners' subjective perceptions of their learning setting (Hanrahan, 1998; Ferguson \& Dorman, 2001; Khine \& Fisher, 2004; Frenzel et al., 2007; Aldridge et al., 2009) and this includes interactions that occur between learners and learners, learners with teachers and learners with the environment.

Few studies in the field of learning environments have been conducted in South Africa. Such studies have been carried out at high school level (Aldridge, Fraser \& Sebela, 2004; Aldridge, Laugksch \& Fraser, 2006; Aldridge, Laugksch, Seopa \& Fraser, 2005), one at tertiary level (Adams, 1997) and one conducted at the primary school level (Aldridge et al., 2009). Research in the field of classroom learning environments will continue to be necessary in South Africa if we indeed support and intend to promote the CFS project initiative of the National Department of Education. Also, to improve implementation of the current curricular reforms in South Africa requires the creation of learning environments which offer 
learners greater opportunities to learn and to succeed in life (UNICEF, 2010; Department of Basic Education, 2011). To provide quality education does not come cheaply. For teachers, they should use child-centred pedagogical approaches and support the development of learners' higher-order thinking (UNICEF, 2010).

In her study, Hanrahan (1998), although she focused on high school Biology learning, she found that the level of cognitive engagement was affected by two interrelated factors: the control the teacher had over almost all activities, and student beliefs about learning in that context. Her data suggested that both intrinsic and extrinsic motivation which could lead to deep involvement in learning were constrained by a dominance of teacher-centred methods of instruction. Aldridge et al. (2009) examined the effectiveness of using feedback from a learning environment instrument to guide improvements in teachers' teaching practice in their primary schools (Grades 4, 5, 6 and 7). Their data revealed that for three of the four scales (Involvement, Task Orientation and Equity) of the learning environment instrument they used, learners preferred a more favourable learning environment from that which they perceived to be actually present. Despite having few learning support materials, some teachers in Aldridge et al. (2009) study were able to involve their learners successfully in the mathematics lessons by providing them with opportunities to work in small groups, discuss their ideas and understandings with each other, and solve problems on their own. Consequently, it was through the lenses of CFS and psychosocial learning environment that I set out to view how mathematics teaching in the context of the recent South African curriculum reforms occurs in one particular rural primary class. Teaching, according to Ball and Cohen (1999:10), "occurs in particulars - particular students interacting with particular teachers over particular ideas in particular circumstances".

The vision of mathematics promoted by the South Africa's National Curriculum Statement (NCS), Curriculum and Assessment Policy Statement (CAPS) for mathematics (Intermediate Phase: Grades 4-6) is based on the view that:

Mathematics is a language that makes use of symbols and notations to describe numerical, geometric and graphical relationships. It is a human activity that involves observing, representing and investigating patterns and quantitative relationships in physical and social phenomena and between mathematical objects themselves. It helps to develop mental processes that enhance logical and critical thinking, accuracy and problem-solving that will contribute in decision-making. (Department of Basic Education, 2011:13)

Thus the teaching of mathematics should support learners in constructing their own connections and ideas (Szydlik, 2000; Tarlow, 2008). Learners should solve problems, communicate ideas both orally and in writing, engage in mathematical reasoning, and search for mathematical connections. As learners build connections between and among different representational systems, their thinking and reasoning is likely to improve (Maher, 2005).

\section{Methodology and Methods}

An action research collaboration (Bishop, 1998; Noffke \& Brennan, 1991) described here was carried out by myself, a university mathematics educator, and a male primary mathematics teacher named Joel. It was conducted over a period of three years (Maoto, 2003). As seen by Bishop (1998:39) "the approach is only action research when it is collaborative". The partnership involved repeated cycles of planning, teaching and reflection with a view to learning about and improving practice (Maoto \& Wallace, 2006). Over the period of the study, the collaboration took different forms, including lessons facilitated by the teacher and observed by me, lessons facilitated by me and observed by the teacher, lessons jointly facilitated as collaborators, reflective sessions following each lesson and joint planning of term activities.

I first met Joel as my student when he was undertaking tertiary studies in mathematics teaching at the University in classes I facilitated. He held a three-year Primary Teachers Diploma and had five years of teaching experience. Joel's school was equipped with sanitary water, telecommunication facilities, sufficient classrooms equipped with desks and chairs, enough textbooks, good supplies of stationery, science equipment, mathematics' teaching aids and a computer laboratory for both teachers and learners. The school was electrified and some classrooms burglar proofed to tighten the security.

In this article I use data gathered during Joel's classroom interactions. We worked together over a period of 12 weeks, for a total of 24 lessons. Typically, my visits included planning meetings prior to each lesson, individual or team teaching, and post-lesson discussions. I use field-notes, journal entries, and lesson transcripts to construct vignettes of two of the lessons taught by Joel. The vignettes are constructed using the strategy of narrative analysis (Polkinghorne, 1995; Søderberg, 2006) whereby characters, events and plots are assembled in narrative form. The vignettes have been selected and constructed to illustrate Joel's teaching practice. Accompanying each vignette is a reflective commentary, on issues pertaining to the central research question: How to create a child friendly psychosocial learning environment in teaching young learners mathematics? This question is explored in more detail in the discussion section of the paper, using Polkinghorne's (1995) analysis of narrative strategy applied to the two vignettes. 
Two major ethical issues were addressed prior to the commencement of the study. The first was related to the teacher participation and the second was related to the learner participation. In the first case, at the start of the collaboration Joel (the acting principal then) was informed of the nature of the study, the purposes, potential audiences and substantive foci of the research. He was made aware that he was free to voice out his opinions, give advice and withdraw if he wanted. In the second case, it was left to him to explain our mission to both learners and their parents, of which he did and permission was granted. Erickson (1998:1161) writes: "consent that is genuinely informed and without coercion reduces the risk of social harm because it affirms the dignity and respects the agency of those who will be involved in the study". I was forthright and specific about what the study involved. I was open to him so that he should not feel compelled (as my student at the start of the study) to participate. I have obtained the written permission from him. It should also be noted that he requested that I use his real name to reflect the genuine nature of our collaboration. While the actual teacher name has been used, the names of learners are pseudonyms.

\section{Findings: Vignettes of Practice}

Vignette one, 'Sharing control and code-switching', describes Joel's attempt to create a learning environment that allows learners to take control of their learning, thus removing the notion of a teacher. The second vignette, 'At home with multiple realities', describes an attempt of exposing learners to an unfamiliar situation with an intention to provoke a higher level of thinking (abstraction).

\subsection{Vignette 1: sharing control and code switching}

Prior to the lesson, Joel explained to me how he adopted a new teaching strategy of letting the learners rotate in leading the class discussions. On entering the class, I found the learners seated in six groups of six. While I was still finding a place at the back to sit, one girl stood up and said: "Ok class let us continue with the corrections". Without hesitation every one of them took out his/her scribbler and they started discussing in their groups question by question. Joel came nearer me and said: "they are discussing how they have attempted questions for our district mathematics common test 1". As he moved from one group to the other questioning and sometimes requesting clarification, it appeared to me that the learners were stuck on one question. The question read:

Six learners attended a class party and ate a variety of food. Something caused them to become ill. John ate pizza, hamburger and pie and became ill. Mpho ate hamburger and pie but not pizza and became ill. Lorraine ate pizza but neither hamburger nor pie and felt fine. Dudu did not eat anything and also felt fine. Refilwe ate pizza and pie but not hamburger and became ill. Jane ate hamburger and pie and stayed away from pizza he also got sick. Determine the food that probably caused the illness.

All I could see was that some learners worked as individuals first, then talked to their neighbours and thereafter joined the bigger group. Joel moved from one group to the other questioning and in certain cases encouraging those who were stuck. It seemed that all learners struggled to make sense of the question. This state of affairs went on for a while until Joel interrupted, saying: "Ok let us all try to attach meaning to this question. Who can explain to us what they understand by this question?" One learner stood up and whilst struggling to explain his understanding in English he stopped and said: "Sir, I want to explain using my mother tongue". Even before Joel could answer all learners agreed and said: "Yes, yes we will understand better". Then the learner explained slowly in Northern Sotho, the local language all understood. Another learner (a boy) then quickly rose up and rushed to the front, picked up a piece of chalk and wrote the following on one corner of the chalkboard:

$$
\begin{aligned}
& \text { John } \rightarrow \text { pizza, hamburger pie } \rightarrow \text { ill } \\
& \text { Mpho } \rightarrow \text { hamburger, pie } \rightarrow \text { ill } \\
& \text { Lorraine } \rightarrow \text { pizza } \rightarrow \text { fine } \\
& \text { Dudu } \rightarrow \text { nothing } \rightarrow \text { fine } \\
& \text { Refilwe } \rightarrow \text { pizza, pie } \rightarrow \text { ill } \\
& \text { Jane } \rightarrow \text { hamburger, pie } \rightarrow \text { ill } \\
& \text { Answeris Pie }
\end{aligned}
$$

One learner (a girl) seated at the back said aloud: "No sir, he can't just write let him explain how he arrived at the answer". The boy who wrote on the chalkboard explained using code-switching; from English to Northern Sotho and back 
to English. For a while learners became engaged in a discussion in their individual groups while Joel remained quiet and moved from one group to the other. This time I could hear voices shouting "I got it" and sometimes expressions of frustration as other learners were still making sense of the question. It seemed that they did not want to accept the summary written at the board. Some were still busy, the bell rang and we went out of the class to the office.

Joel quickly asked me: "Do you think there is anything wrong in allowing code-switching in teaching mathematics?" Joel was indirectly trying to bring language as an issue with regard to this particular activity. It appeared that he felt a bit unsettled when his learners during my presence used their mother tongue. He indicated that his learners made sense of the question after it had been explained using their mother tongue. Although the question had more to do with the reasoning skill, it appeared that learners encountered challenges with the language used. The challenge could have also been created by the type of food mentioned in the activity.

***

Joel succeeded to share 'control' with his learners during classroom interactions. There were indications of good communication between Joel and his learners as well as freedom of choice. On one occasion a learner pointed out that he wanted to explain a question in his mother tongue. Although the learners were still young you could hear them expressing their disagreements on certain cases. This type of interaction marked a success in the creation of a learning environment that engaged learners fully in the learning process. The given problem was novel to the learners, that is, they did not have a ready-made solution procedure. The majority of them initially used a guess or trial-and-error approach, but they realised thereafter that they had to make sense of the problem or the challenge posed.

\subsection{Vignette 2: At home with multiple realities}

Joel exposed his learners to the computer "Math Trek" programme to learn about creating number patterns. As a way of assessing whether they made sense of what they had learned, he quietly wrote the following on the chalkboard: "Look at the following pattern $1 ; 3 ; 5 ; 7 ; 9 ; 11 ;$ - . Can you find the next number I should write?"

One learner: (quickly answered) 13.

Joel: How did you get 13 Thelma?

Thelma: I just guessed.

Another learner: (trying to help Thelma). It is a pattern of odd numbers!

Magoro: It is because we add 2 to get the next number. That is, we add 2 to the previous number to get the next one. Joel at this stage intervened and explained how they could know that their answer was correct. By referring to the numbers on the board he pointed out that it was the addition of two to the last number. Then whilst writing he said: "Here is another pattern 1; 2; 4; 8; 16; 32; -. Come out with the explanation of how this pattern works. How is this pattern formed?"

For a while the learners worked in their groups. As Joel moved from one group to another, learners did not seem to notice him and kept on discussing with each other. He was attracted to one group and he smiled as he observed. I quickly stood up and became interested in what he observed. One learner was trying to convince her group members to listen how she was seeing or considering the pattern to be. She had:

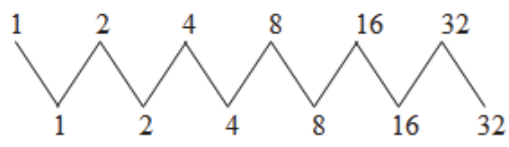

She continued: Every time I add the previous number to itself then you get the next number.

Check: $1+1=2 ; 2+2=4 ; 4+4=8 ; 8+8=16 ; 16+16=32 ; 32+32=64$ therefore the answer will be 64 .

One other member of that same group said: We just continue using times.

Another girl said: No. We add not multiply.

Joel asked: Generally how can you explain this pattern?

This time it seemed that all learners heard Joel's question. It was no longer just one group's question as one learner from another group shouted: "We add each number two times to get the next number." Even before Joel could make some follow-up remark, two learners following each other said: "We add each number one times to get the next". "We add the number that we get to get the second number". There was one girl seated at the back who was quiet for a long time. She stood up, went to the front and said: "To get the next number we multiply the previous number by two". 
Joel asked: Why is that?

She said: It is because the number we will multiply with is a prime number.

What a surprise! I did not expect that kind of reasoning from grade 6 learners. I thought this learner came up with good reasoning and most likely understood the pattern.

Joel: (relaxed) Is 4 a prime number?

Learner: Wait, a prime number is a number having only two factors. Then 4 is not a prime number. (This was the same learner rectifying her mistake)

There was another learner from the group I was seated with. She saw the pattern as:

$2 \times 1=22 \times 2=4 \quad 2 \times 2 \times 2=8 \quad 2 \times 2 \times 2 \times 2=16$ and so on she continued.

She was challenged by the first term of the given number pattern. She was worried that she did not know how to find 1 by multiplication of 2 because $2 \times 0=0$ and not giving her 1 as on the given pattern. I asked her to explain to me how she arrived at repeated multiplication by 2 for the other terms. Unfortunately, she could not explain how. Because Joel did not see her work, she was not given a chance to share her understanding. That was a missed opportunity that could have generated a rich discussion towards generalisation of the given number pattern.

Joel insisted that they should think carefully again to address his question. He said, 'Check the given patterns closely and carefully. Use all the operations to trace how the pattern was formed'. Thereafter, each group was asked to pick up one pattern from the ones given. They had to first find the next number to be written and then explain in writing how the pattern was formed. The patterns given were:

$$
\begin{aligned}
& 53 ; 48 ; 43 ; 38 ;- \\
& 176 ; 167 ; 158 ; 149 ;- \\
& 1 ; 2 ; 4 ; 8 ;- \\
& 26 ; 38 ; 50 ; 62 ;- \\
& 1 ; 4 ; 16 ; 64 ;- \\
& 26 ; 32 ; 38 ; 44 ;-
\end{aligned}
$$

The learner who introduced the multiplication bit in the previous pattern $(1 ; 2 ; 4 ; 8 ; 16 ; 32)$ was seated with the group that Joel shared the discussion with. He used the same reasoning for the pattern $1 ; 4 ; 16 ; 64$; - and had:

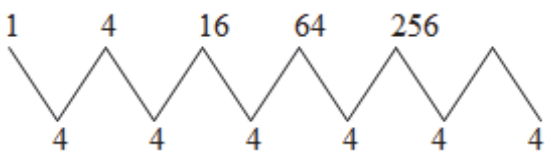

This was the learner who was called to order by one girl who insisted and said: 'No we add not multiply'. Working alone this time, the learner continued and wrote:

$$
\begin{aligned}
& 1 \times 4=4 \\
& 4 \times 4=16 \\
& 16 \times 4=64 \\
& 64 \times 4=256
\end{aligned}
$$

It appeared that this learner was convinced that multiplication was the correct process and it was working. What seemed to be his problem was to convince his group-mates so that they could see what he was seeing. Two other girls who were seated next to him were struggling to confirm his answer by using addition. They had:

$\begin{array}{rr}64 & 64 \\ 64 & 64 \\ +64 & 64 \\ 64 & 64 \\ \overline{2416} & \overline{264}\end{array}$

These two learners looked puzzled but could not detect what their problem was. Repeatedly adding, they seemed not to be getting the answer they were looking for, that was 256 . Joel at that time was seated with another group which was trying to convince him about their responses. At this point, the period was over and we left the classroom.

Joel's learners appeared to be finding it hard during this lesson on 'pattern spotting' to generalise the given patterns to meet new situations. It was exciting when members of the same group failed to convince each other on how they saw the patterns. Some learners could only see addition working while others approached the patterns by applying multiplication. Interestingly, they did not agree on what approach to use. After giving the explanation of how the first 
pattern worked, Joel decided to offer them sufficient time to explore on their own. He appeared relaxed and kept on asking follow-up questions to provoke the learners to think deeper. Joel's questioning skill was excellent. He also seemed not to be worried by the shouts learners made. Learner-learner participation was excellent too. On reflecting on his facilitation Joel commented in the following manner as his journal entry:

I realised ...that follow-up by the teacher to wrong answers given by learners is important. The teacher should not just say to the learner "that is not correct". The teacher should tolerate the learner as there was thinking that led to the wrong answer. The thinking behind which brought the learner to the wrong answer should be investigated by the teacher; through asking the learners questions on how they came to the answer. By explaining, the learners can therefore realise their faults and from that point they can get through to the correct answer. All these are what a mathematics teacher should do by facilitating learners' creative thinking.

From this vignette and Joel's reflection, the following key aspects for creating a psychosocial learning environment emerges: the importance of asking follow-up searching questions, tolerance by the teacher, respect for learners' responses, the teacher's investigation of learners' responses or learners' thinking, encouragement of learners' explanation and self-correction. Joel's mathematics teaching was mostly characterised by a shift towards merging process and product. He further regarded reflection as playing a major role in his teaching. To this he added:

... I have to reflect in order to improve on the next day. In class the reflections help me to see whether I presented well ... if not what area needs to be improved. I learned on how to find my learners' difficulties and to encourage them to improve.

***

The learning situations illustrated in the two vignettes present opportunities for communication and mathematical reasoning. Learners were exposed to an environment that offered them opportunities to make conjectures and arguments. As they began to make conjectures, they discussed ideas. Joel guided the conversations by asking prompting questions that required his learners to clarify their ideas. He was never tempted to supply answers or tell learners when they were correct. Instead, he played a role of scaffolding learners to communicate effectively and make good mathematics arguments. He stopped worrying about the learners' shouts as they disagreed and he provided freedom to code switch from English to their mother tongue to try to make sense of the questions. Thus, teacher-learner relationship was such that there was openness, respect for every learner's ideas and freedom of expression. He felt at home with multiple realities and catered for learner-learner participation.

\section{Discussion}

This article aims to explore the question, 'How to create a child friendly psychosocial learning environment in teaching young learners mathematics?' Focus was on one particular case, primary teacher's (Joel) attempt in teaching problem solving in Grade 6 (learners aged 11 years to 12 years). Although I cannot make generalisations based on a single case study, looking closely at the growth of the learners' mathematical ideas and movement through their representations, however, gives me a window into what kinds of learning environments we should create and how. The findings have several implications for mathematics teachers, with respect to classroom practices, and the teacher-learner interpersonal relationship in the creation of child friendly psychosocial learning environment.

\subsection{Give learners a sense of control}

To ensure learners achieve our intended learning outcomes, we must control the direction of classroom learning activities to some extent. However, we can give our learners a sense that they, too, control some aspects of classroom life. For example, we have seen how Joel supported his learners to make some choices, allowing them to direct the lesson proceedings and to code-switch as they struggled to make sense of the given activity. In that way, they felt accepted as members of the classroom community.

\subsection{Create a sense of community in the classroom}

Learners are free to work in situations in which they realise that the teacher is a partner in their learning. It was the interactions, mutual respect and support of one another's efforts that encouraged all learners to share their different 
representations. The pleasant atmosphere created, made them believe that everyone makes an important contribution to classroom learning. Joel adopted a new teaching strategy of letting the learners rotate in leading the class discussions. It was during classroom discussions that Joel pursued learners' ideas and opinions. When learners share a sense of community, they are more likely to exhibit prosocial behaviour such as sharing and cooperation, stay on task, express enthusiasm about learning activities, and achieve at high levels.

\subsection{Value all learners' learning}

Learners seek out friendly relationships, acceptance and high regard of those around them, that is, needs for affiliation and for approval. Teachers can help learners meet such needs through their own actions. For example being good listeners during classroom discussions give learners confidence to explore further. When learners believe that their teachers are genuinely caring and supportive, they have higher self-efficacy (Ferguson \& Dorman, 2001); find learning activities more interesting and enjoyable and are more likely to ask for help when they need it. We should guard against imposing mathematical ideas on learners. Learners should be allowed time to develop own ideas in environments that encourage them to build, refine, and connect meaningful, personal representations (Tarlow, 2008).

\subsection{Involve and give support to all learners during problem solving activities}

The data also reveals learners in Joel's class being free to voice their frustrations. For example, they supported the learner who struggled in vignette 1 to explain his interpretation of the activity in English. It was that support that later gave all learners confidence to code-switch when stuck. The learning environment created validated the importance of giving all learners the chance to be involved personally, whether in small-group learning, individually or whole class discussion. In vignette 2 learners were observed working on multiple-solution problems. While the classroom activities may have been initiated by tasks or ideas from the textbooks, it was Joel who was actively involved in pursuing the discussions. He responded to his learners' learning by being more curious and that led to him reflect on his learners' learning on the spot. Also, the tasks given were at the appropriate level. Thus, it was easier for Joel to support learners and gradually withdrew as they became more independent.

\subsection{Balance telling and listening}

The data reveals that Joel limited the use of telling learners mathematics procedures during his teaching practice. He encouraged learners to participate and share their ideas in class, thus a move towards learner autonomy. This was evident forthright in vignette 1 which indicated a shared control of the learning process through a promotion of teacherlearner and learner-learner relationships, characterised by values of respect for every learner's ideas and freedom of expression. Joel was observed asking learners questions that facilitated the use of higher-order thinking skills. That was possible because he was observed to being present to and with learners' learning process. He asked follow-up questions after incorrect responses were given and pursued learners' thinking. Being present was being learning centred. Being learning centred requires a teacher who is a good listener to learners' thinking rather than listening for only the right answer (Maoto, 2003). Thus, it requires a teacher who could appropriately and delicately balance telling and listening (Maoto \& Wallace, 2006), in what Lampert (1985) refers to as 'dilemma management'.

\section{Conclusion}

This study took place in South Africa in the context of major curriculum reform. Many mathematics teachers are still grappling with questions relating to improvement of quality teaching and learning (UNICEF, 2010). Among such questions is, 'How to create a child friendly psychosocial learning environment in teaching young learners mathematics?' Lessons to be learned on creation of productive learning environments particularly in primary schools remain important (Aldridge et al., 2009). A child friendly learning environment stimulates learners' engagement in the learning process and influences their behaviour. Besides that, it also assists in the development of learners' skills and cognitive abilities. From the findings in this article, a creation of such child friendly psychosocial learning environments would require a teacher who is ready to:

- give learners a sense of control

- create a sense of community in the classroom

- value all learners' learning 
- involve and give support to all learners during problem solving activities

- balance telling and listening.

The extent, to which these findings can be applied to a new situation, must be based on a judicious comparison of the contexts.

\section{References}

Adams, W.E. (1997). Science laboratory environment in a South African college of education: The effect of class membership. South African Journal of Education, 17: 49-52.

Aldridge, J., Fraser, B. \& Ntuli, S. (2009). Utilising learning environment assessments to improve teaching practices among in-service teachers undertaking a distance-education programme. South African Journal of Education 29: 147-170.

Aldridge, J.M., Fraser, B.J. \& Sebela, M.P. (2004). Using teacher action research to promote constructivist learning environments in South Africa. South African Journal of Education, 24: 245-253.

Aldridge, J.M., Laugksch, R.C. \& Fraser, B.J. (2006). School-level environment and outcomes-based education in South Africa. Learning Environments Research, 9: 123-147.

Aldridge, J.M., Laugksch, R.C., Seopa, M.A. \& Fraser, B.J. (2005). Development and validation of an instrument to monitor the implementation of outcomes-based learning environments in science classrooms in South Africa. International Journal of Science Education, 9: 123-147.

Ball, D.L. \& Cohen, D.K. (1999). Developing practice, developing practitioners: Toward a practice-based theory of professional education. In L. Darling-Hammond \& G. Sykes (eds.), Teaching as the learning profession: Handbook of policy and practice: 332. San Francisco: Jossey-Bass.

Bishop, A.J. (1998). Research, effectiveness, and the practitioners' world. In A. Sierpinska \& J. Kilpatrick (eds), Mathematics education as a research domain: $A$ search for identity. Dordrecht, The Netherlands: Kluwer.

Department of Basic Education. (2011). National Curriculum Statement: Curriculum and Assessment Policy Statement (CAPS): Mathematics Intermediate Phase Grades 4-6. Pretoria: Government printing works.

Erickson, F. (1998). Qualitative research methods for science education. In B.F. Fraser \& K.G. Tobin (eds.), International handbook of science education: 1155-1173. Kluwer, Dordrecht, The Netherlands.

Ferguson, J.M. \& Dorman, J.P. (2001). Psychosocial classroom environment and academic efficacy in Canadian High School mathematics classes. The Alberta Journal of Educational Research XLVII(3): 276-279.

Frenzel, A.C., Pekrun, R. \& Goetz, T. (2007). Perceived learning environment and students' emotional experiences: A multilevel analysis of mathematics classrooms. Learning and Instruction 17: 478-493.

Hanrahan, M. (1998). The effect of learning environment factors on students' motivation and learning. International Journal of Science Education, 20(6): 737-753.

Junaid, M.I. (2011). An evaluation of the COL-UNICEF child friendly school projects in Swaziland, Lesotho, Botswana and South Africa: A report for the Commonwealth of Learning.

Khine, M.S. \& Fisher, D.L. (2004). Teacher interaction in psychosocial learning environments: cultural differences and their implications in science instruction. Research in Science \& Technological Education, 22(1): 99-111.

Lampert, M. (1985). How do teachers manage to teach? Perspectives on problems in practice. Harvard Educational Review, 55(2): 178194.

Maher, C.A. (2005). How students structure their investigations and learn mathematics: Insights from a long-term study. Journal of Mathematical Behavior, 24: 1-14.

Maoto, R.S. (2003). Mathematics teacher learning in the context of South African outcomes-based education reforms. DEd thesis. Australia: Curtin University of Technology.

Maoto, S. \& Wallace, J. (2006). What does it mean to teach Mathematics for understanding? When to tell and when to listen? African Journal of Research in Mathematics, Science and Technology Education, 10(1): 59-70.

Noffke, S.E. \& Brennan, M. (1991). Student teachers' use of action research: Issues and examples. In BR Tabachnick \& KM Zeichner (eds). Issues and practices in inquiry-oriented teacher education. London: Falmer.

Polkinghorne, D.E. (1995). Narrative configuration in qualitative analysis. In JA Hatch \& R Wisniewski (eds). Life history as narrative. London: Falmer.

Søderberg, A.M. (2006). Narrative interviewing and narrative analysis in a study of a cross-border merger. Management International Review, 46: 397-416.

Szydlik, J.E. (2000). Photographs and committees: Activities that help students discover permutations and combinations. The Mathematics Teacher, 93(2): 93-99.

Tarlow, L.D. (2008). Sense-able combinatorics: Students' use of personal representations. Mathematics teaching in the middle school, 13(8): 484-489.

UNICEF. (2010). Child friendly schools evaluation: Country report for South Africa. United Nations Children's Fund, New York. 